\title{
Coletivo Bee, luta LGBTT e saúde integral: diversidade sexual e de gênero no ambiente universitário
}

\author{
Bee collective, LGBTT fight and integral health: sexual and gender \\ diversity in the university environment
}

\section{Colectivo Bee, lucha LGBTT y salud integral: diversidad sexual y de género en el medio ambiente universitario}

Claudio José dos Santos Júnior ${ }^{1, a}$

claudiosantos al@hotmail.com | http://orcid.org/oooo-0002-2853-1968

John Victor dos Santos Silva ${ }^{1, b}$

john.setedejulho@gmail.com | http://orcid-org/0000-0003-4671-102X

Eden Erick Hilário Tenório de Lima ${ }^{1, c}$

edendelima@gmail.com | https://orcid.org/oooo-0003-1114-1207

Waldez Cavalcante Bezerra ${ }^{1, d}$

waldezto@yahoo.com.br | https://orcid.org/o000-0001-7178-4074

${ }^{1}$ Universidade Estadual de Ciências da Saúde de Alagoas. Maceió, AL, Brasil.

a Graduando em Medicina pela Universidade Estadual de Ciências da Saúde de Alagoas.

b Graduando em Enfermagem pela Universidade Estadual de Ciências da Saúde de Alagoas.

c Mestrado em Sociologia pela Universidade Federal de Alagoas.

d Mestrado em Serviço Social pela Universidade Federal de Alagoas.

\section{Resumo}

O presente artigo trata-se de um trabalho descritivo sobre o Coletivo Bee, um movimento estudantil pertencente à Universidade Estadual de Ciências da Saúde de Alagoas que surgiu com o objetivo de implantar o movimento LGBTT na Universidade para discutir o preconceito de gênero e de orientação sexual, por meio de ações de empoderamento e de emancipação das minorias LGBTTs. Ao longo de sua trajetória, o Coletivo desenvolveu atividades como reuniões para discussão das temáticas relacionadas ao movimento, organização de eventos, atividades de protestos, cyber ativismo, participação na regulamentação e implantação do uso do nome social, entre outras atividades com finalidade de trazer a reflexão sobre a cidadania e a saúde da população LGBTT. Sua importância esteve concentrada na integração de lésbicas, gays, bissexuais, travestis e transexuais à sociedade e, sobretudo, na busca de assegurar o direito ao acesso integral aos serviços da rede pública de saúde e fortalecer a Política Nacional de Saúde Integral LGBTT na formação universitária.

Palavras-chave: Movimento social; Minorias sexuais; Equidade em saúde; Saúde holística; Relações Interpessoais; Política Nacional de Saúde Integral LGBTT. 


\begin{abstract}
This article is about a descriptive work about the Bee Collective, a student movement belonging to the State University of Health Sciences of Alagoas, which came up with the objective of implanting the LGBTT movement in the University to discuss gender bias and sexual orientation, through actions of empowerment and emancipation of LGBTT minorities. Throughout its history, the Collective has developed activities such as meetings to discuss issues related to the movement, organization of events, protest activities, cyber activism, participation in regulation and implementation of the social name, among other activities to bring the reflection on the citizenship and health of the LGBTT population. Its importance was focused on the integration of lesbians, gays, bisexuals, transvestites and transsexuals into society and, above all, in the quest to ensure the right to full access to public health services and to strengthen the National LGBTT Comprehensive Health Policy in university education.
\end{abstract}

Keywords: Social movement; Sexual minorities; Equity in health; Holistic health; Interpersonal relationships; National Policy on Comprehensive LGBTT Health.

\title{
Resumen
}

Este artículo trata sobre un trabajo descriptivo sobre Bee Collective, un movimiento estudiantil perteneciente a la Universidad Estatal de Ciencias de la Salud de Alagoas, que tuvo el objetivo de implantar el movimiento LGBTT en la universidad para discutir el sesgo de género y la orientación sexual, a través de acciones de empoderamiento y emancipación de las minorías LGBTT. A lo largo de su historia, el Colectivo ha desarrollado actividades como reuniones para discutir temas relacionados con el movimiento, organización de eventos, actividades de protesta, ciberactivismo, participación en la regulación y la implementación del nombre social, entre otras actividades para llevar la reflexión sobre la ciudadanía y salud de la población LGBTT. Su importancia se centró en la integración de lesbianas, gays, bisexuales, travestis y transexuales en la sociedad y, sobre todo, en la búsqueda de garantizar el derecho al pleno acceso a los servicios de salud pública y de fortalecer la Política nacional de salud integral LGBTT en la educación universitaria.

Palabras clave: Movimiento social; Minorías sexuales; Equidad en salud; Salud integral; Relaciones interpersonales; Política nacional de salud integral LGBTT.

INFORMAÇÕES DO ARTIGO

Este texto compõe o dossiê 40 anos do movimento LGBT no Brasil: visibilidades e representações.

Contribuição dos autores:

Concepção e desenho do estudo: Claudio José dos Santos Júnior.

Aquisição, análise ou interpretação dos dados: Claudio José dos Santos Júnior, John Victor dos Santos Silva.

Redação do manuscrito: Claudio José dos Santos Júnior, John Victor dos Santos Silva, Eden Erick Hilário Tenório de Lima, Waldez Cavalcante Bezerra.

Revisão crítica do conteúdo intelectual: Claudio José dos Santos Júnior, John Victor dos Santos Silva, Eden Erick Hilário Tenório de Lima, Waldez Cavalcante Bezerra.

Declaração de conflito de interesses: não há.

Fontes de financiamento: não houve.

Considerações éticas: não houve.

Agradecimentos/Contribuições adicionais: ao Coletivo Bee e ao Movimento Estudantil da Universidade Estadual de Ciências da Saúde de Alagoas.

Histórico do artigo: submetido: 05 fev. 2019 | aceito: 23 maio 2019 | publicado: 12 set. 2019.

Apresentação anterior: não houve.

Licença CC BY-NC atribuição não comercial. Com essa licença é permitido acessar, baixar (download), copiar, imprimir, compartilhar, reutilizar e distribuir os artigos, desde que para uso não comercial e com a citação da fonte, conferindo os devidos créditos de autoria e menção à Reciis. Nesses casos, nenhuma permissão é necessária por parte dos autores ou dos editores. 


\section{Introdução}

Pode-se entender os movimentos sociais como uma das expressões mais diversificadas e organizadas da sociedade, tendo como finalidade a subversão dos códigos simbólicos hegemônicos e de uma reconstrução mais inclusiva de interpretações das sociedades ${ }^{1}$; o que possibilita conquistas no âmbito dos direitos (liberdades individuais, serviços públicos, reformas políticas, igualdade, entre outros) e da cultura (perspectiva sustentável, percepção de injustiças sociais, denúncia de diferentes formas de discriminação etc.). Sua atuação é marcada por diferentes formas de mobilizações, visando sempre alguma mudança² ${ }^{2}$.

Um dos movimentos sociais que vem ganhando visibilidade no Brasil é o LGBTT ${ }^{\mathrm{i}}$ que define a luta das lésbicas, gays, bissexuais, travestis, transexuais, entre outras minorias sexuais, pela igualdade de direitos e políticas públicas que alcancem essa população. Assim, estratégias como as Paradas do Orgulho LGBTT, protestos, ativismo, passeatas, ajudaram a trazer notoriedade para as questões relacionadas à discriminação, intolerância e violências sofridas por esse grupo.

Reconhecendo, então, a importância de discutir sobre as demandas da população LGBTT, ainda pouco abordadas dentro das Universidades, um grupo de alunos da Universidade Estadual de Ciências da Saúde de Alagoas (Uncisal) criou um movimento estudantil para trazer à tona as repressões, discriminações e preconceitos que discentes LGBTTs vinham sofrendo no âmbito acadêmico com o objetivo de levantar a bandeira da Luta LGBTT e buscar respeito, direitos e representatividade dentro da Universidade, além de promover capacitações e atividades que favorecessem uma melhor construção da assistência em saúde para esse público.

A Universidade Estadual de Ciências da Saúde de Alagoas é instituição educacional vinculada ao Poder Executivo do Estado de Alagoas e tem como finalidade promover a educação superior e profissionalizante, bem como também valorizar a cultura geral e a ciência. A Universidade conta atualmente com quinze cursos de graduação na área de saúde, sendo cinco bacharelados e oito tecnológicos, além de treze programas de residência em saúde e mais de vinte cursos de formação profissional de nível técnico. A Uncisal possui oito unidades de saúde, entre hospitais-escola e centros especializados em diagnósticos. Juntos, esses serviços atendem a uma demanda de 420 leitos e somam mais de mil e quinhentos procedimentos mensais gratuitos, o que confere a uma média de $15 \%$ dos atendimentos à saúde do Estado de Alagoas por meio do Sistema Único de Saúde³.

Dessa maneira, o presente trabalho tem como objetivo relatar as circunstâncias e motivações que levaram à criação do movimento 'Coletivo Bee - Luta LGBTT' no âmbito da Uncisal, apresentando sua trajetória e ações desenvolvidas na instituição e para a comunidade.

\section{O Coletivo Bee - luta LGBTT}

O Coletivo Bee é um movimento formado por estudantes da Uncisal que surgiu no ano de 2016 com o objetivo de discutir aspectos relacionados aos preconceitos de gênero e orientação sexual, por meio de ações de empoderamento e de emancipação das minorias LGBTTs. A primeira conduta do Coletivo foi criar um espaço dentro da Universidade para promover a discussão da temática e aproximação de discentes da comunidade LGBTT e simpatizantes da causa para a construção de um programa de ações para a realização de atividades relacionadas à quebra de tabus e paradigmas entre estudantes, docentes e técnicos da instituição.

Um dos pilares motivadores para o surgimento do Coletivo Bee foi, além da falta de representatividade do grupo LGBTT nos espaços da Universidade, a necessidade de reivindicação e de resistência frente à

\footnotetext{
i Ressalte-se que o movimento LGBTT não deve ser pensado como unificado, mas composto pelas mais diversas manifestações e organizações, que se colocam como representantes das causas dessa população. Sendo assim, suas pautas podem figurar de maneira polissêmica, mas com grau considerável de afinidade.
} 
discriminação sofrida por parte de algumas/alguns integrantes da comunidade acadêmica. Para tanto, o Coletivo realizou reuniões mensais abertas ao público para debater temas ligados à saúde LGBTT e aspectos gerais do movimento gay, trans e lésbico. Foram problematizados diversos temas e incitadas discussões importantes no âmbito institucional e extra-institucional. Dentre essas temáticas, destacaram-se os debates sobre 'o desafio de sair do armário'; 'as dificuldades de ser LGBTT na Uncisal'; 'impactos da Lei Estadual Escola Sem Partidoii para a educação de Alagoas'; 'estratégias de desconstrução e combate ao preconceito contra LGBTTs dentro e fora do ambiente acadêmico'; 'gênero como categoria social'; 'sexualidade e orientação sexual'; 'identidades sociais e sistemas de opressão, dominação ou discriminação'; e 'as questões de gênero e os serviços de saúde’.

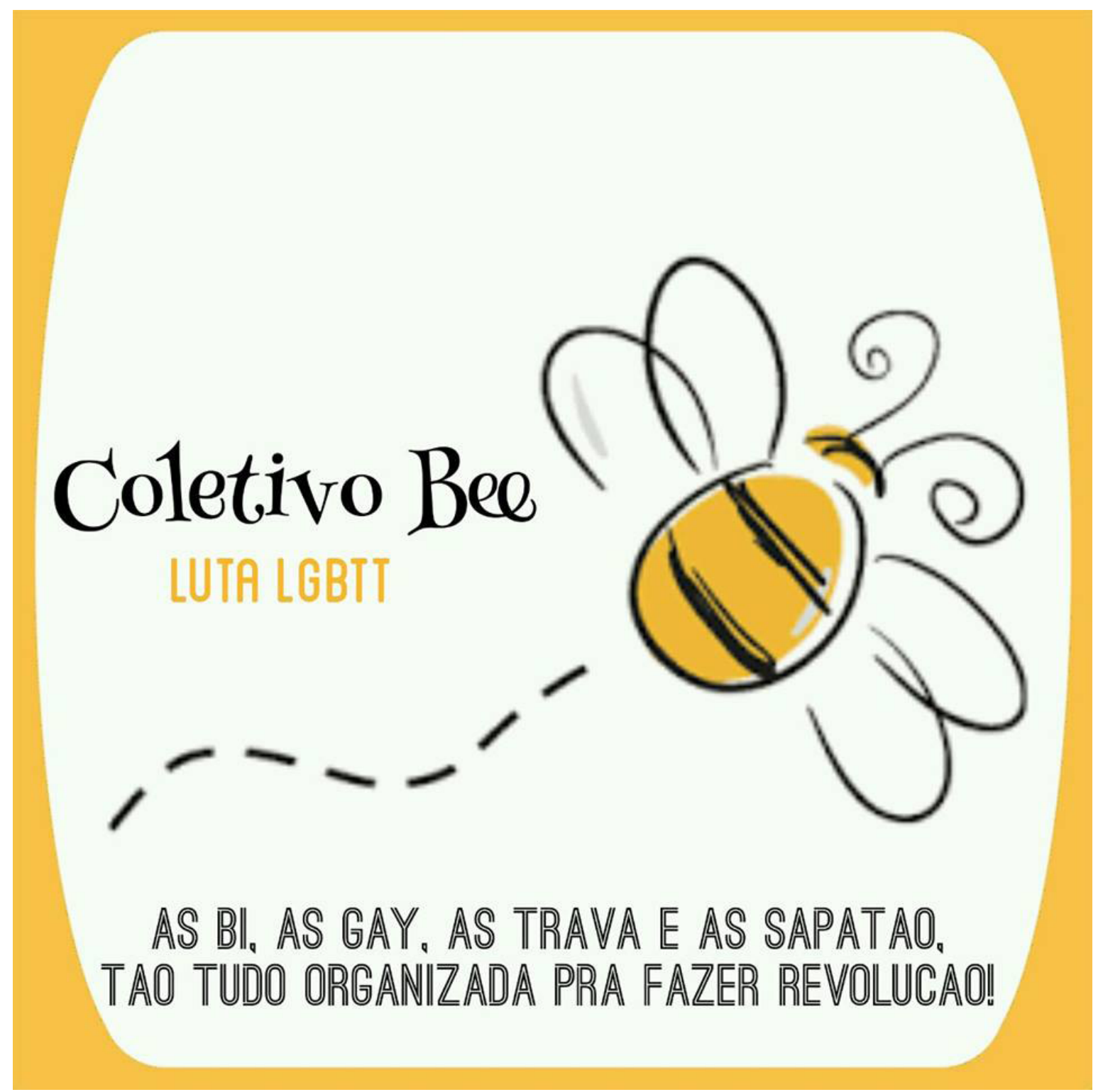

Figura 1 - Identidade Institucional do Coletivo Bee - Luta LGBTT Fonte: Acervo dos autores.

ii A lei estadual no 7.800/2016 de autoria do deputado Ricardo Nezinho, batizada de 'Escola Sem Partido', foi aprovada pela Assembleia Legislativa do Estado de Alagoas em 28 de abril de 2016 após veto do governador. A norma proibia "a prática de doutrinação política e ideológica" nas instituições alagoanas sob o princípio do "direito dos pais a que seus filhos menores recebam a educação moral livre de doutrinação política, religiosa ou ideológica". De acordo com a Lei, todos os professores eram obrigados a manter "neutralidade" em sala de aula e estavam impedidos de expressar suas opiniões perante os alunos em relação a temas políticos, religiosos e ideológicos, sob pena de advertências e, inclusive, demissão. Em 21 de abril de 2017, o ministro Roberto Barroso, do Supremo Tribunal Federal, concedeu uma liminar declarando sua inconstitucionalidade e suspendendo na íntegra os efeitos da regulamentação. 
Concomitantemente ao desenvolvimento das reuniões, foram realizadas ações de protesto, ativismo, cyber ativismo, cine debates, entre outras. Destaca-se a execução de três campanhas na Universidade, por meio de colagem de cartazes, o que proporcionou maior visibilidade para o Coletivo e para as suas discussões no espaço interno da instituição. As duas primeiras campanhas foram voltadas para a exposição de frases e relatos de LGBTTfobia, escritos em folhas e colados nos corredores da Universidade. A última consistiu na colagem de frases e mensagens de apoio e de incentivo à comunidade LGBTT.

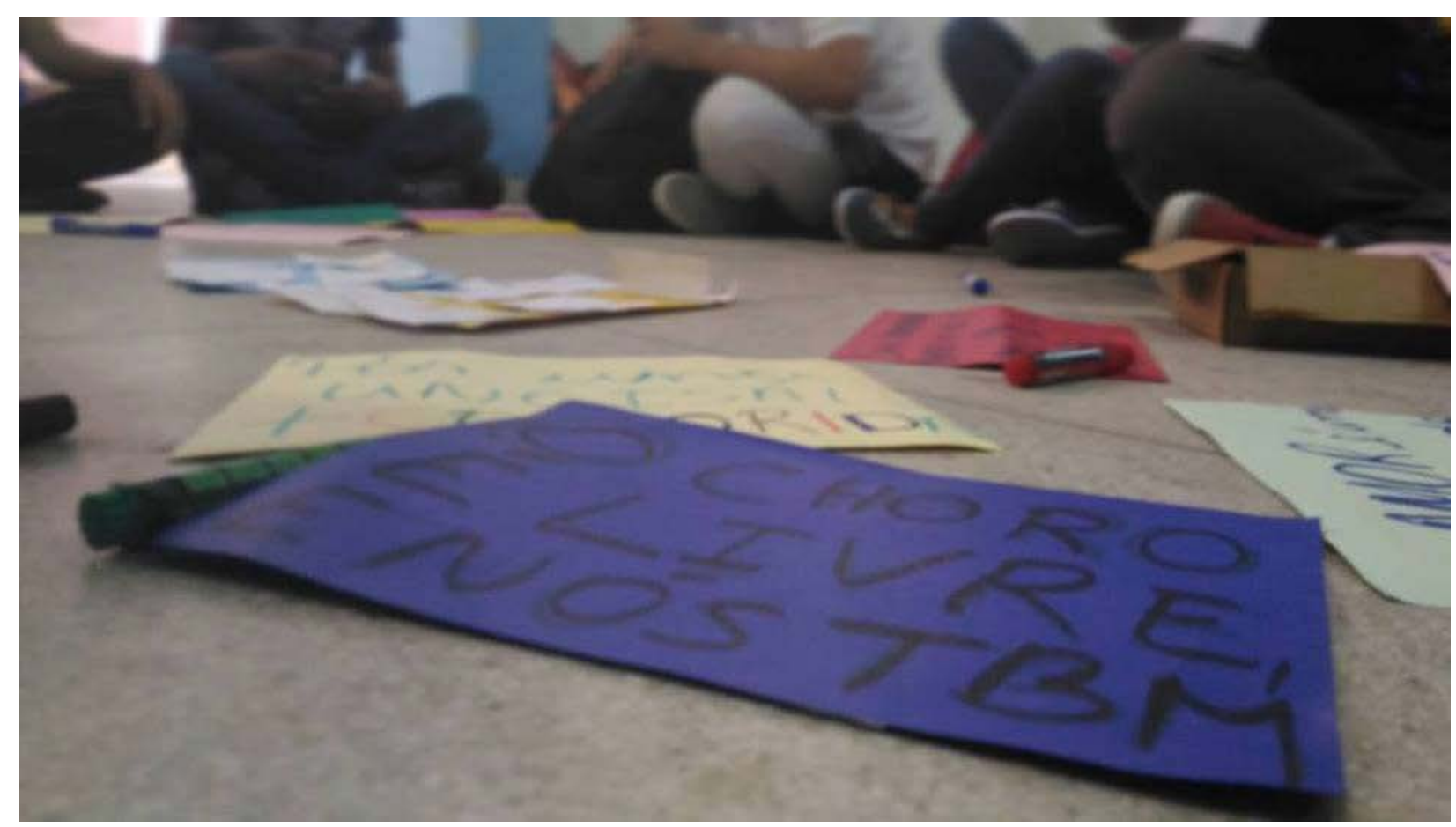

Figura 2 - Ação dos cartazes nos murais da Universidade sobre respeito à população LGBT Fonte: Acervo dos autores.

Para dar um alcance maior às questões trazidas, o Coletivo criou uma página na rede social Facebook ${ }^{\mathrm{iii}}$ e um grupo social que reuniu os seus membros e apoiadoras/es do movimento. Ambos os espaços foram utilizados para o compartilhamento de vivências, divulgação de ações e de campanhas externas, além de emissão de notas e posicionamentos.

Sendo a internet um local que facilita a fluidez das identidades, o ciberespaço, apesar de ser um ambiente de disputa e de construção identitária, se mostra um espaço potente de vivência e ativismoº ${ }^{2}$. No âmbito virtual, foi possível encontrar uma grande variedade de conteúdo que exibe as diversas expressões de relações afetivas e sexuais humanas, indicando que as repressões sociais com relação à sexualidade nesse meio são limitadas.

O Coletivo Bee também protagonizou momentos fora do ambiente da Uncisal, por meio da participação de alguns dos seus membros em debates, palestras, mesas redondas e rodas de conversas promovidas por instituições parceiras. Dentre estes momentos, destacam-se o 'Espaço Dandara', que discutiu sobre a População LGBTTI durante a I Mostra de Políticas Afirmativas em Saúde de Alagoas; a roda de conversa 'LGBTTFOBIA: vivências, dificuldades e caminhos para a superação', durante o Encontro Regional dos Estudantes de Medicina (EREM); a mesa redonda 'Saindo do casulo: a coragem de ser quem se é', promovida pelo Curso de Serviço Social da Universidade Tiradentes (Unit); a palestra 'Identidade de gênero, orientação afetiva-sexual e sexo: precisamos falar sobre isso', organizada pelo Centro Acadêmico de Psicologia do

iii Página do Coletivo Bee na rede social Facebook: www.facebook.com/coletivoLGBTTdauncisal. 
Centro Universitário CESMAC; e a mesa 'Disforia de gênero ou identidade de gênero: uma discussão entre a psicologia e o direito', idealizada pelo Centro Acadêmico de Psicologia da UNIT.

Em dois anos de atuação, o Coletivo Bee conseguiu reconhecimento como movimento legítimo por parte da comunidade acadêmica da Uncisal, principalmente das/os gestores da instituição. Esse reconhecimento levou o grupo a participar junto à administração da Universidade do processo de debate, regulamentação e implementação do uso do nome social para discentes, servidoras/es e pacientes que se identificam como travestis, transexuais, transgêneros e intergêneros no âmbito dos registros acadêmicos, profissionais e nos documentos diversos emitidos pelos setores de registro e controle acadêmico e funcional e pelas clínicas e hospitais-escolas mantidos pela Instituição. Tal garantia foi conquistada a partir de uma série de reuniões do Coletivo Bee com a Pró-Reitoria Estudantil e com a Pró-Reitoria de Gestão de Pessoas da Universidade, tendo sido o produto dessa articulação três minutas de portarias que tratavam da política de utilização do nome social pelas categorias de discentes, servidoras/es e comunidade externa nos espaços da Uncisal. Tais normativos foram oficialmente aprovados pelo Conselho Superior Universitário (CONSU), por meio das Portarias $n^{0} 023 / 2017,140 / 2017$ e 263/2017.

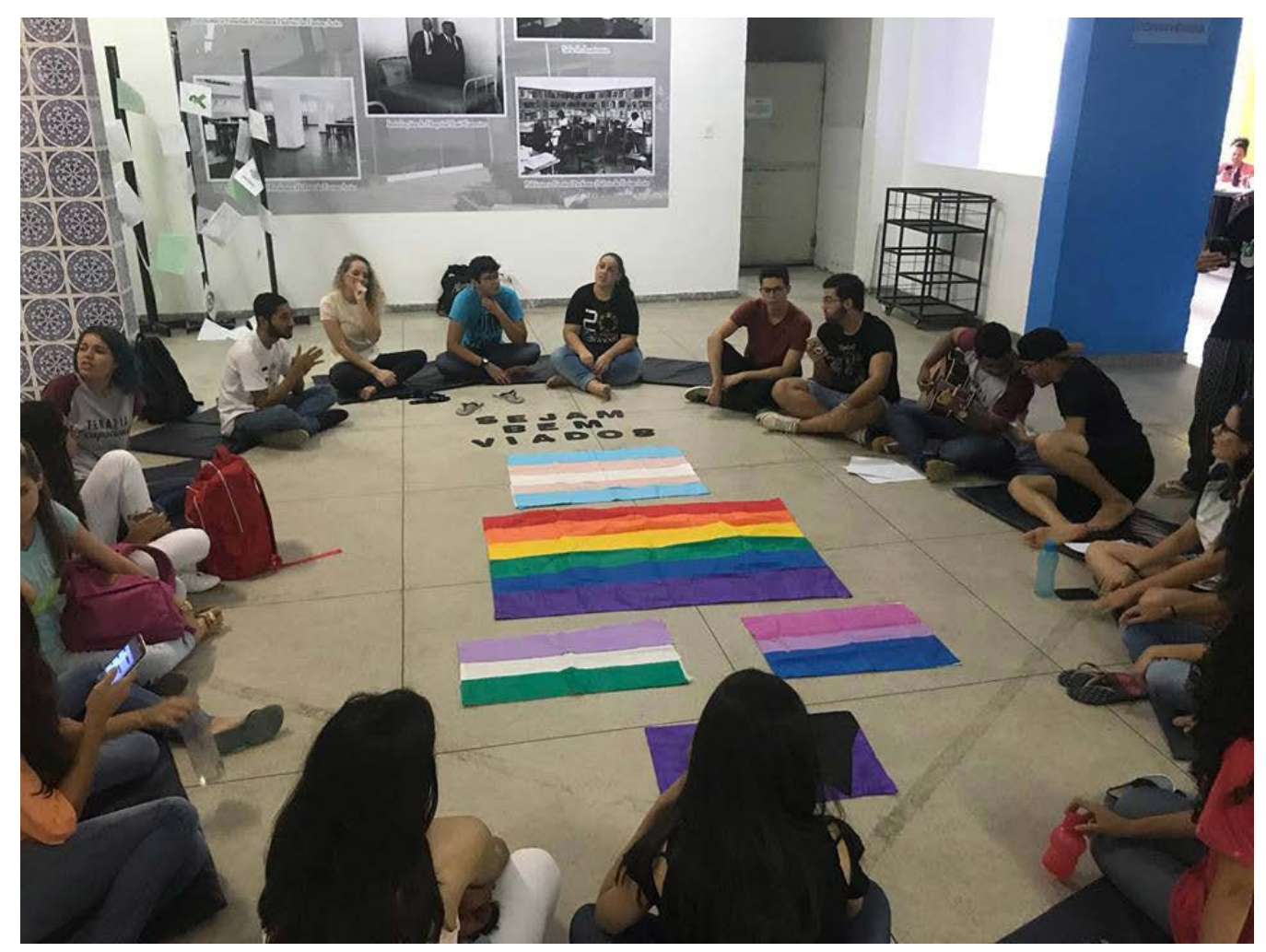

Figura 3 - Roda de conversa junto aos estudantes sobre o uso do nome social na instituição Fonte: Acervo dos autores. Foto autorizada.

Cabe ressaltar que o uso do nome social já é permitido a travestis e transgêneros no Sistema Único de Saúde (SUS) como um direito garantido pela Portaria n ${ }^{0}$ 1.820/2009 do Ministério da Saúde. Documentos e prontuários do SUS possuem campo para inserção do nome social, de modo a respeitar a maneira como se identificam e gostam de ser chamadas/os. Essa medida garante às/aos usuárias/os o cumprimento dos preceitos do SUS de equidade, igualdade e universalidade da assistência e dos serviços a todas/os as/os cidadãs/ãos brasileiras/os ${ }^{5}$.

Como estratégia complementar aos normativos de utilização do nome social, o Coletivo articulou com o Núcleo de Educação Permanente das Unidades da Uncisal a realização de oficinas e palestras com os setores administrativos e com diretórios e centros acadêmicos com a finalidade de divulgar o normativo e esclarecer minúcias sobre o seu texto. Tais momentos foram, para além da abordagem de pormenores 
acerca do nome social, proporcionadores de qualificação do público interno para lidar com as demandas relativas às questões de gênero e orientação sexual.

A partir das iniciativas do Coletivo, a comunidade acadêmica pôde perceber a necessidade urgente de propor uma política institucional para abordagem dessas temáticas enquanto parte da rotina da Universidade. As ações do Coletivo Bee foram o ponto de partida para o início de discussões e para o enfrentamento de uma problemática ainda maior, que era a ausência da abordagem daqueles assuntos nos currículos dos cursos de graduação da instituição.

É um grande desafio para os cursos de saúde das universidades inserirem nos seus componentes curriculares disciplinas ou temáticas sobre a assistência em saúde para populações específicas, em especial ao público LGBTT. Os cursos geralmente oferecem a discussão sobre o assunto em aulas pontuais, não havendo uma disciplina obrigatória nos currículos para tratar dessas questões. Quando há, são disciplinas optativas onde apenas as/os alunas/os interessadas/os frequentam as aulas. Isso se torna uma problemática, haja vista que é preciso trabalhar para a desmistificação acerca da patologização das questões de gênero, fazendo refletir sobre como vem sendo construída a assistência em saúde para essas pessoas ${ }^{6}$.

Assim sendo, os objetivos do Coletivo Bee passaram a ser, também: o monitoramento da implementação de ações de saúde para as pessoas LGBTTs no âmbito do Estado de Alagoas e da Uncisal; a formulação e proposição de ações voltadas para o enfrentamento à discriminação, para a promoção e defesa do direito à saúde integral dessa população; a discussão de assuntos importantes para esse público, como forma de assegurar o acesso integral - e livre de preconceitos - aos serviços da rede pública de saúde; a discussão dos avanços nos princípios da igualdade e equidade do Sistema Único de Saúde (SUS) frente à Política Nacional de Saúde Integral LGBTT; e o fortalecimento da luta pela causa LGBTT, incentivando a implantação de políticas públicas que assegurem um melhor atendimento a esse público nas unidades de saúde.

Nesse mesmo período, surgiu também o ‘Grupo de Estudos sobre Gênero, Diversidade e Saúde’, vinculado ao 'Grupo de Pesquisa Saúde e Comunidade: buscando a integralidade do saber', cadastrado no CNPq, com o objetivo de fomentar a discussão científica e a produção acadêmica sobre as políticas públicas de saúde e as questões de identidade, orientação sexual e de gênero. Também foi criado um grupo institucional para discussão e fortalecimento de políticas afirmativas em intercâmbio entre gestores, docentes e discentes, por iniciativa destas/tes últimas/os em reação a situações LGBTTfóbicas no âmbito da instituição, que cobraram providências junto à Pró-Reitoria Estudantil.

\section{Atividades de extensão desenvolvidas pelo Coletivo}

A Extensão constitui um dos pilares da Universidade e tem a finalidade de contribuir para o desenvolvimento social da comunidade por meio de atividades relacionadas principalmente à promoção da saúde e qualidade de vida dos sujeitos. A comunicação entre a Universidade e a comunidade favorece a propagação de ações que trabalhem o cuidado em saúde, as questões de gênero e sexualidade e possibilita que essas ações alcancem a população alvo e favoreçam a desmistificação relacionada à saúde da população LGBTT, quebrando tabus e desfazendo os preconceitos criados a respeito da assistência em saúde para esse público%

Desse modo, o Coletivo Bee também foi responsável por realizar atividades de extensão com o intuito de proporcionar às/aos estudantes de diversas instituições de ensino, familiares e comunidade externa em geral, momentos de aprendizado e reflexão sobre as questões de gênero e diversidade. E por se tratar de um movimento estudantil de uma universidade pública de ciências da saúde, o desafio foi falar sobre o cuidado e assistência em saúde a esse público específico. 


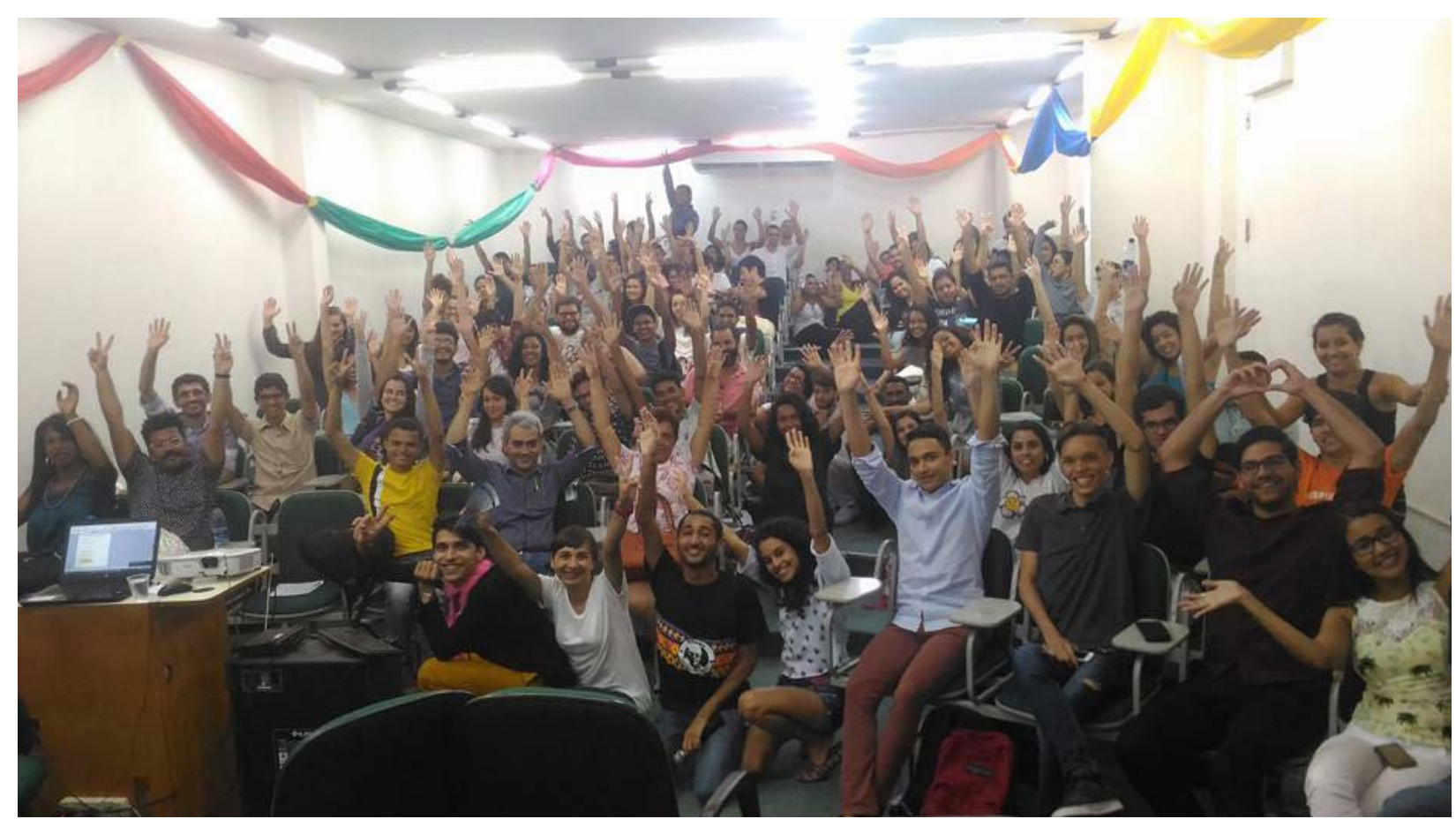

Figura 4 - Fórum de Saúde Integral da População LGBTT+ de Alagoas, realizado pelo Coletivo Bee Fonte: Acervo dos autores. Foto autorizada.

Para tanto, o grupo concentrou esforços para a realização de dois eventos. O primeiro, denominado 'Seminário de Saúde LGBTTI: desafios da equidade em tempos de intolerância', realizado em novembro de 2016, reuniu 120 participantes, entre universitárias/os, profissionais de saúde, integrantes de movimentos sociais e membros da sociedade civil. Contou com discussões conduzidas por pesquisadoras/es da área de ciências da saúde e de educação que se dedicam ao estudo da temática LGBTT. Os temas das atividades foram abordados sob a forma de mesas-redondas, que versaram sobre 'as práticas homofóbicas no Brasil'; 'as diferenças entre gênero, identidade de gênero e orientação sexual'; 'os desafios para implementação da Política Nacional de Saúde LGBTTI'; 'a patologização, a exclusão e a marginalização das/os transexuais e travestis'; e 'existe preconceito na Universidade?'.

A realização deste evento também contribuiu para a consolidação do Coletivo Bee enquanto instituição de representação do público LGBTT na Uncisal e fora dela, uma vez que proporcionou um rico momento de debate e troca de experiências com os demais Coletivos LGBTTs do estado de Alagoas. Estiveram presentes representantes do Coletivo Tamanca e do Coletivo Quilombo Púrpura, ambos da Universidade Federal de Alagoas (Ufal), Coletivo Rosas do Asfalto, do Instituto Federal de Alagoas (Ifal), e dos Centros Acadêmicos de diversas Instituições de Ensino Superior do estado. O seminário contou ainda com a participação de integrantes e profissionais da Associação das Travestis e Transexuais de Alagoas (ASTTAL), que puderam relatar as dificuldades da população trans em enfrentar a discriminação e a falta de oportunidades no âmbito profissional e acadêmico. Contou ainda com uma performance drag queen de uma artista local, que marcou a finalização do evento e trouxe para a Universidade uma prática cultural bastante difundida e aderida pelo público LGBTT.

Ainda é muito escassa a discussão sobre as questões de gênero no espaço da universidade e, quando há, acontece de forma isolada e pontual em cada curso. É preciso entender que os debates sobre a população LGBTT precisam ser de forma interdisciplinar, incluindo, para tanto, os setores de saúde, educação, segurança, assistência social, entre outros. Devem ser levadas em consideração as questões culturais desse público, não apenas os aspectos biológicos ${ }^{4}$. Embora a mídia venha contribuindo para a desconstrução do tabu sobre a sexualidade, algumas questões precisam de melhores esclarecimentos, principalmente em se 
tratando da saúde do público LGBTT. Assim sendo, a Universidade se torna uma das instituições propícias para a realização de ações sobre saúde e diversidade sexual ${ }^{8}$.

Pela carência de espaços que abordem a temática no estado de Alagoas e a consolidação como lugar de discussão da temática de saúde LGBTT dentro e fora da Uncisal, o grupo realizou, em parceria com o Diretório Central dos Estudantes da Uncisal (DCE), um segundo evento em outubro de 2017. Decorrente de um amadurecimento do Coletivo e da própria definição da palavra 'seminário' - que possui em sua essência uma relação verticalizada e acadêmica de transmissão de informações, onde um/a orador/a 'expõe' e as/ os demais absorvem o conteúdo da exposição - o evento passou a ser denominado 'Fórum', por ter um formato que contempla o intercâmbio de informações entre as/os participantes.

O Fórum teve como nome e tema norteador 'A saúde Integral da população LGBTT+ de Alagoas: entre teorias e práticas'. Entre outras discussões, propôs-se a traçar um panorama das necessidades da comunidade LGBTT de Alagoas, bem como o que esta comunidade entendia como sendo essencial para o equacionamento das suas demandas de saúde e as estratégias necessárias para superar a difícil realidade que enfrenta nos serviços de saúde. Estiveram presentes 112 participantes, com representatividade tão diversa quanto a primeira edição, incluindo desde membros da academia até interessados sem nenhuma vinculação com o grupo LGBTT e/ou com o meio universitário.

O evento contou com cinco mesas redondas: 'Políticas públicas para a população LGBTT+: o que queremos?', protagonizada por membros dos Coletivos LGBTTs de Alagoas; 'Políticas públicas para a população LGBTT+: onde estamos?', de iniciativa do Grupo Gay de Alagoas (GGAL) e do Conselho Municipal LGBTT, com participação da gerência de políticas públicas da Secretaria Estadual de Saúde de Alagoas (SESAU); 'Saúde sexual e atenção integral à mulher lésbica, bissexual e trans', conduzida por um grupo de mulheres lésbicas, bissexuais e transexuais usuárias dos SUS; 'Arte é Saúde? O cenário da arte Drag em Alagoas', em que as participantes foram profissionais que alavancam a cultura da arte da drag queen no cenário local; 'Os invisíveis no sistema de saúde: abordagem da população Tc, atividade encabeça pela ONG Pró-Vida LGBTT, uma organização que atua na promoção da saúde, da cidadania e em busca da garantia de Direitos Humanos de travestis e mulheres transexuais de Alagoas.

Além das discussões, o Fórum contou ainda com apresentações culturais de artistas locais LGBTTs, tais como performances musicais e de dança, encenações teatrais e declamação de poemas, todas elas expressões artísticas com mensagens de cunho social e que envolviam situações vivenciadas e/ou presenciadas pela população-alvo do evento.

Momentos como esses reafirmam a importância de se conhecer a cultura da população LGBTT, pois essas questões são parte constitutivas dos sujeitos e que fazem diferença na forma como os demais veem, se relacionam e trabalham com eles. A caracterização no corpo representa, para esses sujeitos, uma forma de empoderamento e, sobretudo, afirmação da sua pessoa na sociedade, e isso deve ser valorizado pelas/os profissionais de saúde no processo de compreensão dos aspectos relacionados à saúde desse grupo?

Este segundo evento cumpriu com seu papel de discutir as Políticas de Saúde LGBTT, incorporando o conceito ampliado dos determinantes sociais no processo saúde-doença. O espaço pôde despertar as/ os participantes para o exercício de alteridade e empatia por meio da utilização das diferentes linguagens (artística, científica e cultural) e para a problematização do tema 'Saúde da população LGBTT'.

\section{Desestabilizando normatividades}

As percepções acerca da realidade se dão, majoritariamente, a partir da produção de sentidos conduzida por grupos hegemônicos, que se empenham na construção de significados acerca dos sujeitos, bem como dos comportamentos e dos modos de ser. Essa produção não só determina o que deve ser considerado normal, mas também os argumentos que fundamentam tal normalidade ${ }^{1}$. 
Para a disseminação dessas narrativas e, consequentemente, o exercício do domínio de determinados grupos sobre outros, é importante que controlem os mecanismos que auxiliem em tal difusão. $\mathrm{O}$ aparato técnico-científico, as agências de informação e comunicação e os centros de decisão política são apontados por Alberto Melucci ${ }^{1}$ como detentores de poder, que manipulam dimensões da vida:

a) privadas: o corpo, a sexualidade, as relações afetivas;

b) subjetivas: processos cognitivos e emocionais, motivos, desejos;

c) biológicas: estrutura do cérebro, o código genético, a capacidade reprodutiva.

Pierre Bourdieu ${ }^{10}$ afirma que algumas instituições sociais como o Estado, a Família e a Escola são importantes para a realização do que chama de processo de des-historicização. Ou seja, o domínio sobre os mecanismos de difusão e o controle simbólico das percepções sobre a realidade realizam um esquecimento da história, de maneira a ocultar a genealogia de tais normalidades, que tiveram sua construção em determinado tempo e espaço, mas que são difundidas como atemporais e universais.

É dessa maneira que se institui a heteronormatividade como única via legítima no que concerne à sexualidade. E se muitas vezes as instituições religiosas - especificamente as de tradição judaico-cristãs - são pensadas como as principais condutoras dessa verdade construída, é importante não esquecer da continuidade do fortalecimento dessa simbologia no domínio que a ciência exerce sobre a produção do conhecimento na contemporaneidade - sobretudo a ciência biomédica ${ }^{11}$. Sendo assim, se por um lado a religião impõe sua tradição e dá continuidade ao seu processo de universalização baseando-se em suas narrativas sagradas, a ciência, por outro lado, mesmo consciente da falibilidade e da mutabilidade do conhecimento que produz, não deixa de exercer seu poder de classificação da realidade e, de alguma maneira, dar continuidade ao processo de des-historicização, quando se limita a pensar a dimensão biológica como 'alfa' e 'ômega' da sexualidade humana.

Alberto Melucci ${ }^{1}$ entende os movimentos sociais como contestadores desses signos hegemônicos. Para tal, os movimentos se valem de diversas estratégias, muitas delas voltadas à negação e subversão dos mecanismos e das narrativas dominantes. Assim, as pautas colocadas pelo movimento LGBTT como a criminalização da LGBTTfobia, as propostas de legitimação e legalização de arranjos familiares homoafetivos, a despatologização das transexualidades e a reivindicação por políticas públicas específicas ao público LGBTT - são exemplos de demandas que ultrapassam a luta por direitos no campo da política institucional, mas que atingem a esfera da ressignificação das normalidades impostas. Destacam-se ainda as paradas da diversidade como uma forma de ressignificar também os modelos de manifestações usuais dos movimentos sociais, muitas vezes criticadas, mas que carregam uma força muito intensa no sentido de repensar as maneiras de buscar legitimidade e de contestar a normatividade posta.

É nesse sentido que se pode interpretar a atuação do Coletivo Bee no âmbito da Universidade Estadual de Ciências da Saúde de Alagoas (Uncisal), pois as ações descritas acima têm forte caráter contestador. Suas atividades, não raro, têm sido consideradas incômodas por levar as pessoas alcançadas a sair de sua zona de conforto no que se refere às normatividades instituídas. O feedback dos incômodos se dá em algumas reações específicas, como nas mensagens preconceituosas e, muitas vezes religiosas, que foram escritas na intervenção com cartazes com frases LGBTTfóbicas. Tal fato demonstra que, se por um lado houve reflexão à tal normalidade instituída, por outro, há resistências que testificam a presença de uma normatividade.

Outro incômodo às ações contestatórias do Coletivo Bee foi a reação a uma mensagem de boas-vindas em um dos eventos promovidos, que dizia 'Sejam Bem Veados!'. Essa frase serviu para dar expressão à presença do movimento na universidade, pois foi muito lembrada posteriormente, não raro, sob uma ótica de censura. E tal reação já é sintomática de que há normatividades sendo desestruturadas.

Pode-se ir mais além com relação ao caráter contestador do Coletivo Bee, quando se percebe, sobretudo, as reações de nível institucional para com as ações do movimento, como a restrição do uso dos murais, o cancelamento dos agendamentos de espaços físicos para a realização dos eventos, a reação negativa da gestão para a presença de performances de drag queens na programação dos eventos, a afirmação da gestão 
de que não haveria necessidade para a existência de tal grupo por não haver LGBTTfobia na Uncisal e o conselho de que a sexualidade deveria ser tratada como algo individual.

Tais reações, ao contrário do que dizem representar, demonstram a urgência dos espaços de discussões sobre a temática e o desvelamento das LGBTTfobias cotidianas e institucionalizadas. Dessa maneira, o Coletivo Bee critica, tal como na visão de Melucci sobre os movimentos sociais, as lógicas estabelecidas, nesse caso, o padrão biomédico estabelecido ao longo da história da instituição. Em conjunto com outras movimentações - tais como a criação de um grupo de pesquisa, a presença de disciplinas que discutem políticas afirmativas e alteridade, o ingresso de professoras/es de formação diversa à área de saúde, a criação de grupo em parceria entre gestão, docentes e discentes para a discussão de políticas afirmativas - a atuação do Coletivo leva a um processo de ressignificação quanto à presença de determinadas questões na instituição e na formação de profissionais da saúde.

\section{Diálogos do Coletivo Bee com a política nacional de saúde integral LGBTT}

As bases norteadoras da assistência em saúde no Brasil, defendidas pelo Movimento de Reforma Sanitária, inscritas na Constituição Federal de 1988 e reafirmadas nas Leis 8080/90 e 8142/90, apontam para a construção de políticas de saúde que tomem como foco das suas ações o sujeito em suas singularidades, afirmando o direito universal, igualitário e equitativo de todos acessarem os serviços de saúde e terem as suas necessidades atendidas, sem distinção de qualquer tipo (classe social, religião, cor, raça, gênero, orientação sexual etc. $)^{12}$.

Contudo, o processo histórico da realidade tem comprovado que a máxima da igualdade de acesso aos serviços de saúde não é uma prática concreta na vida de determinados grupos populacionais, a exemplo do LGBTT, colocando-se a necessidade da criação de políticas de equidade, uma vez que ao se evidenciar as especificidades de grupos sociais distintos, com necessidades de saúde diferenciadas, tornam-se necessárias ações governamentais também diferenciadas ${ }^{13}$. Dessa forma, se existem grupos historicamente marginalizados e que possuem dificuldades de acesso aos serviços de saúde, é preciso viabilizar e otimizar este acesso.

Assim, fruto da luta do movimento LGBTT, o Ministério da Saúde lançou, em 2004, o Programa Brasil sem Homofobia ${ }^{14}$ e em 2011 foi instituída a Portaria ${ }^{0} 2.836^{15}$, que criou a Política Nacional de Saúde Integral de Lésbicas, Gays, Bissexuais, Travestis e Transexuais, a qual visa promover a saúde integral desse grupo populacional, eliminando a discriminação e o preconceito institucional e contribuindo para a redução das desigualdades e para consolidação do SUS como sistema universal, integral e equitativo.

Uma das inovações trazidas pela Política Nacional de Saúde Integral LGBTT é o reconhecimento das categorias orientação sexual e identidade de gênero como determinantes sociais de saúde e que, portanto, a discriminação por tais condições incide diretamente na saúde desencadeando processos de sofrimento, adoecimento e morte prematura decorrentes do preconceito e do estigma social reservado às pessoas LGBTT. Além desse aspecto, diversas garantias à população LGBTT passam a ser reconhecidas no âmbito dos serviços de saúde, com vistas a respeitar as singularidades desse grupo, dentre elas destacam-se: o direito ao uso do nome social; a elaboração de protocolos para realização de hormonioterapia e implantes de próteses de silicone; promoção do respeito em todos os serviços do SUS, evitando constrangimentos no uso de banheiro e nas internações em enfermarias ${ }^{15}$.

Porém, apesar dos avanços conquistados pelo movimento LGBTT no campo da política de saúde, estudos apontam que muitos são os desafios para a garantia do acesso e cuidado integral à saúde da população LGBTT, sendo os principais limitadores a heteronormatividade e a homofobia, além das crenças religiosas e da biologização da sexualidade, que colocam o sexo biológico como determinante de gênero do indivíduo e o relacionamento afetivo entre pessoas do sexo oposto como o correto ${ }^{16}$.

Nesse sentido, a luta da população LGBTT volta-se para a desconstrução do caráter de anormalidade atribuído pela sociedade às suas escolhas e comportamentos. Tal luta passa a ser travada em diversos setores sociais, inclusive no da saúde, cujo cuidado muitas vezes lhes é negado por julgamentos e preconceitos por parte dos profissionais de saúde responsáveis por seu atendimento, evidenciando a necessidade de se 
repensar a formação desses profissionais e do papel das instituições de ensino superior, juntamente como os órgãos de saúde, na qualificação das/os profissionais no atendimento à população LGBTT ${ }^{13,17}$.

É, portanto, nesse contexto que se insere a atuação do Coletivo Bee. Enquanto movimento originário no âmbito de uma universidade responsável pela formação de profissionais de saúde de diversas áreas, sua atuação foi fundamental para pautar a discussão sobre as necessidades de saúde da população LGBTT em Alagoas, tanto em nível da formação quanto do campo assistencial.

No âmbito interno da Uncisal, as ações realizadas provocaram a gestão e a comunidade acadêmica sobre a pertinência de pautar conteúdos relacionados à saúde integral LGBTT nos currículos dos cursos, ao mesmo tempo em que desvelava as inquietações e o preconceito, muitas vezes institucional, sobre tais demandas, como descrito no item anterior. Neste item, coloca-se em destaque o papel dos dois eventos realizados pelo Coletivo, cujo foco foi problematizar e discutir a temática da saúde LGBTT e promover o encontro e a articulação de diversos atores sociais (estudantes, profissionais de saúde e áreas afins, movimentos sociais, membros da comunidade em geral, entre outros) em prol da temática.

Os eventos se configuraram como espaços formativos que podem refletir na mudança de práticas de cuidado junto a essa população, uma vez que as discussões retiraram o foco da vinculação direta entre a população LGBTT e as ISTs/aids e tornaram evidentes as demais particularidades que envolvem o cuidado integral em saúde desse grupo ${ }^{18}$. Desse modo, as ações do Coletivo contribuíram para informar e divulgar outros aspectos da Política Nacional de Saúde Integral LGBTT, reforçando o imperativo de que a atenção à saúde da população LGBTT esteja vinculada a um cuidado integral, desmistificando a necessidade exclusiva de prevenção de ISTs, incluindo na pauta do cuidado desde o respeito ao nome social até os processos de transexualidade, a despatologização das questões de gênero e as demais especificidades que possam ser relatadas por esta população, com vistas a diminuir a discriminação e o preconceito.

Por fim, outra ação que pode contribuir para a melhora na qualidade do acesso e do cuidado ofertado à população nas unidades assistenciais da própria Uncisal (hospitais escola, ambulatório, centro de reabilitação etc.) foi a realização das oficinas e palestras nos setores administrativos dessas unidades sobre o uso do nome social. Tal estratégia educativa é parte fundamental para o respeito aos normativos aprovados no Conselho Universitário e, consequentemente, para uma relação mais respeitosa, acolhedora e humanizada junto à população trans nesses serviços, evitando-se que julgamentos e valores morais pessoais se estendam aos espaços de produção do cuidado.

\section{Considerações finais}

A nova face da sociedade demanda mobilizações de parte da comunidade tendo em vista o princípio de que, apesar de que todo cidadão é igual perante a Lei, sem distinção de qualquer natureza, ainda existem grupos considerados minorias. É nessa vertente que os movimentos sociais, de maneira geral, contribuem para a tentativa de ampliar os direitos e estender a cidadania a todos os indivíduos, promovendo ações em defesa da integração do ser humano junto à coletividade. Surgem, assim, os coletivos sociais como organizações autônomas, flexíveis, integradoras e não centralizadas, que funcionam de acordo com a demanda das problemáticas situacionais, sobretudo o processo de exclusão perante a sociedade.

O Coletivo Bee desenvolveu inúmeras atividades com o objetivo de implementar o movimento LGBTT no âmbito da Universidade para discutir aspectos relacionados ao preconceito de gênero e de orientação sexual e a emancipação das minorias LGBTTs. Sua importância esteve concentrada na integração de lésbicas, gays, bissexuais, travestis e transexuais e para além disso, uma vez que suas atuações buscaram também assegurar o direito ao acesso integral aos serviços da rede pública de saúde e o fortalecimento da Política Nacional de Saúde Integral LGBTT. 


\section{Referências}

1. Melucci A. Qué hay de nuevo en los "nuevos movimientos sociales"? In: Gusfield J, Rodríguez-Cabello EL. Los nuevos movimientos sociales: de la ideología a la identidad. Madrid: Centro de Investigaciones Sociológicas;1994. p.119-150.

2. Severo DO, Hoefel MGL, Shimizu H. Redes Sociais, Facebook e debate político: olhares dos movimentos sociais. Ciências Sociais Unisinos [Internet]. 2017 [citado em 2019 fev. 3]; 53(2):194-201. Disponível em: https://bit.ly/2TuXVN8.

3. Universidade Estadual de Ciências da Saúde de Alagoas. Comissão Própria de Avaliação. Relatório de Autoavaliacão [Internet]. Maceió-AL: Uncisal; 2018 [citado em 2019 fev. 3]. Disponível em: https://bit. Iy/2UERM13.

4. Santos GGC. Movimento LGBTT e partidos políticos no Brasil. Contemporânea [Internet]. 2017 [citado em 2019 fev. 3];6(1):179-212, 2016. Disponível em: https://bit.ly/2TuQy8e.

5. Silva LKM, Silva ALMA, Coelho AA, Martiniano CS. Use of the social name in the Brazilian Public Health System: elements for the debate on assistance provided to transvestites and transsexuals. Physis: Rev Saude Colet [Internet]. 2017 [citado em 2019 fev. 3]; 27(3):835-846. Disponível em: https://bit. Iy/2UDoUpI.

6. Santos GBS. Elaboração de um componente curricular sobre atenção à saúde da população LGBTT em um Curso de Graduação em Medicina [dissertação]. Natal: 2017. Universidade Federal do Rio Grande do Norte; 2017. 40p.

7. Brêtas JBS, Freitas MJD, Zanatta LF, Godoi AML, Moraes JB, Ricardo LS, Furtado BM. Corpo, gênero e sexualidade: práticas de extensão universitária. Rev Ci Exten [Internet]. 2015 [citado em 2019 fev. 3]; 11(1):100-115. Disponível em: https://bit.ly/2WEa8B7.

8. Miskolci R, Pelúcio L. Gênero, sexualidades e mídias contemporâneas: do pessoal ao político. Rev Estud Feminist [Internet]. 2017 [citado em 2019 fev. 3]; 25(1):263-268. Disponível em: https://bit.ly/2G8ZJIO.

9. Costa LD, Barros AD, Prado EAJ, Sousa MF, Cavadinha ET, Mendonça AVM. Competência Cultural e Atenção à Saúde da população de lésbicas, gays, bissexuais travestis e transexuais (LGBTT). Tempus Actas Saude Colet [Internet]. 2017 [citado em 2019 fev. 3];11(1):105-119. Disponível em: https://bit. Iy/2UBSAUr.

10. Bourdieu P. A dominação masculina. Maria Helena Kühner, tradutora. 4. ed. Rio de Janeiro: Bertrand Brasil; 2005.

11. Foucault M. História da Sexualidade I: a vontade de saber. 9. ed. Rio de Janeiro: Graal; 1998.

12. Sena AGN, Souto. Avanços e desafios na implementação da Política Nacional de Saúde Integral LGBTT. Tempus Actas Saude Colet [Internet]. mar. 2017 [citado em 2019 fev. 3];11(1):09-28. Disponível em: https://bit.ly/2UC912T.

13. Prado EAJ, Sousa MF. Políticas públicas e a saúde da população LGBTT: uma revisão integrativa. Tempus Actas Saude Colet [Internet]. mar. 2017 [citado em 2019 fev. 3];11(1):69-80. Disponível em: https://bit. ly/2WDQuWO.

14. Ministério da Saúde (BR). Conselho Nacional de Combate À Discriminação. Programa Brasil sem Homofobia: programa de combate à violência e à discriminação contra GLTB e promoção da cidadania homossexual [Internet]. Brasília; 2004 [citado em 2019 fev. 3]. Disponível em: https://bit.ly/2qBwbKg.

15. Ministério da Saúde (BR). Portaria No 2.836, de 01 de Dezembro de 2011. Aprova a Política Nacional de Atenção Básica, estabelecendo a revisão de diretrizes e normas para a organização da Atenção Básica, para a Estratégia Saúde da Família (ESF) e o Programa de Agentes Comunitários de Saúde (PACS). DOU [Internet]. 2011 [citado em 2019 fev. 3]. Disponível em: https://bit.ly/1zeuTTi.

16. Carrara S. Discriminação, políticas e direitos sexuais no Brasil. Cad. Saúde Pública [Internet]. 2012 jan [citado em 2019 fev. 3];28(1):184-189. Disponível em: https://bit.ly/2DQcB3P.

17. Popadiuk GS, Oliveira DC, Signorelli MC. A Política Nacional de Saúde Integral de Lésbicas, Gays, Bissexuais e Transgêneros (LGBTT) e o acesso ao Processo Transexualizador no Sistema Único de Saúde (SUS): avanços e desafios. Ci Saude Colet [Internet]. 2017 jan [citado em 2019 fev. 3]; 22(5):15091520. Disponível em: https://bit.ly/2SnDJPR.

18. Santos AR, Santos RMM, Souza ML, Boery RNSO, Sena ELS, Yorld SD. Implicações bioéticas no atendimento de saúde ao público LGBTT. Rev Bioét [Internet]. 2015 [citado em 2019 fev. 3]; 23(2): 400408. Disponível em: https://bit.ly/2Bh4v2M. 